\title{
Maintenance of antifracture efficacy over 10 years with strontium ranelate in postmenopausal osteoporosis
}

\author{
J-Y. Reginster • J-M. Kaufman • S. Goemaere • J. P. Devogelaer • C. L. Benhamou • \\ D. Felsenberg • M. Diaz-Curiel • M-L. Brandi • J. Badurski • J. Wark • A. Balogh • \\ O. Bruyère $\cdot$ C. Roux
}

Received: 14 June 2011 / Accepted: 3 November 2011 / Published online: 29 November 2011

(C) The Author(s) 2011. This article is published with open access at Springerlink.com

\begin{abstract}
Summary In an open-label extension study, BMD increased continuously with strontium ranelate over 10 years in osteoporotic women $(P<0.01)$. Vertebral and nonvertebral fracture incidence was lower between 5 and 10 years than in a matched placebo group over 5 years $(P<0.05)$. Strontium ranelate's antifracture efficacy appears to be maintained long term. Introduction Strontium ranelate has proven efficacy against vertebral and nonvertebral fractures, including hip, over
\end{abstract}

J.-Y. Reginster $(\bowtie) \cdot O$. Bruyère

Department of Public Health and Health Economics,

University of Liège,

Liège, Belgium

e-mail: jyreginster@ulg.ac.be

J.-M. Kaufman · S. Goemaere

Ghent University Hospital,

Ghent, Belgium

J. P. Devogelaer

St-Luc University Hospital, Université catholique de Louvain, UCL 5390,

1200 Brussels, Belgium

C. L. Benhamou

Unité INSERM U658, Rheumatology Department,

CHR d'Orléans,

Orléans, France

D. Felsenberg

Klinik und Poliklinik für Radiologie und Nuklearmedizin

Zentrum für Muskel- und Knochenforschung,

Hindenburgdamm 30,

12203 Berlin, Germany

M. Diaz-Curiel

Servicio de Medicina Interna, Fundacion Jimenez Diaz,

Avenida de los Reyes Catolicos 2,

28040 Madrid, Spain
5 years in postmenopausal osteoporosis. We explored longterm efficacy and safety of strontium ranelate over 10 years. Methods Postmenopausal osteoporotic women participating in the double-blind, placebo-controlled phase 3 studies SOTI and TROPOS to 5 years were invited to enter a 5 year open-label extension, during which they received strontium ranelate $2 \mathrm{~g}$ /day ( $n=237,10$-year population). Bone mineral density (BMD) and fracture incidence were recorded, and FRAX ${ }^{\circledR}$ scores were calculated. The effect of

M.-L. Brandi

Dipartimento di Endocrinologia, Policlinico Careggi,

Viale Pieraccini, 6,

50139 Firenze, Italy

J. Badurski

Center of Osteoporosis and Osteo-articular Diseases,

Bialystok 15-461, Poland

J. Wark

Department of Medicine and Bone \& Mineral Service, Royal Melbourne Hospital, University of Melbourne,

4th Floor, Clinical Sciences Building, Grattan Street,

VIC 3050 Parkville, Australia

A. Balogh

Department of Obstetrics and Gynaecology, Medical and Health Sciences Center, University of Debrecen,

Debrecen, Hungary

C. Roux

Hôpital Cochin, Université Paris Descartes,

Paris, France 
strontium ranelate on fracture incidence was evaluated by comparison with a FRAX ${ }^{\circledR}$-matched placebo group identified in the TROPOS placebo arm.

Results The patients in the 10-year population had baseline characteristics comparable to those of the total SOTI/ TROPOS population. Over 10 years, lumbar BMD increased continuously and significantly $(P<0.01$ versus previous year) with $34.5 \pm 20.2 \%$ relative change from baseline to 10 years. The incidence of vertebral and nonvertebral fracture with strontium ranelate in the 10year population in years 6 to 10 was comparable to the incidence between years 0 and 5 , but was significantly lower than the incidence observed in the FRAX ${ }^{\circledR}$-matched placebo group over 5 years $(P<0.05)$; relative risk reductions for vertebral and nonvertebral fractures were $35 \%$ and $38 \%$, respectively. Strontium ranelate was safe and well tolerated over 10 years.

Conclusions Long-term treatment with strontium ranelate is associated with sustained increases in BMD over 10 years, with a good safety profile. Our results also support the maintenance of antifracture efficacy over 10 years with strontium ranelate.

Keywords BMD $\cdot$ Long-term treatment $\cdot$ Osteoporotic fracture $\cdot$ Strontium ranelate

\section{Introduction}

Osteoporosis is a chronic disease requiring chronic treatment. It is therefore essential to evaluate the efficacy and safety of osteoporosis treatments for the longest time possible, i.e. well beyond the 3 to 5 years recommended by the regulatory authorities. Thus, clinical studies for the bisphosphonates zoledronic acid, risedronate, and alendronate have been extended to 6,7 , and 10 years, respectively [1-3]; the selective estrogen receptor modulator raloxifene has been evaluated up to 8 years $[4,5]$; and results at 5 to 6 years are available for the human monoclonal antibody denosumab [6, 7]. These studies generally indicate sustained increases in the surrogate marker of antifracture efficacy, bone mineral density (BMD). The study designs, notably excluding a placebo group for ethical reasons, preclude direct measurement of long-term reductions in fracture incidence.

The orally active agent strontium ranelate is indicated for the management of postmenopausal osteoporosis. Its mode of action in osteoporotic bone includes opposite effects on resorption and formation, which is associated with an improvement in the material or structural properties of bone [8]. Two international, double-blind, placebo-controlled phase 3 studies in postmenopausal women with osteoporosis, the Spinal Osteoporosis Therapeutic Intervention (SOTI) and Treatment of Peripheral Osteoporosis (TROPOS) trials, demonstrated the efficacy of strontium ranelate in reducing the risk of vertebral, nonvertebral, and hip fracture in a subgroup of patients at high risk $[9,10]$. This efficacy was found to be independent of baseline risk factors [11] and to be maintained over 5 years against placebo [12] with a good safety profile. Results of a pooled extension study of the SOTI and TROPOS populations to 8 years [13] suggested the maintenance of the antifracture efficacy over 8 years of continuous treatment with strontium ranelate. In this article, we describe the results of a pooled longer-term open-label extension of the SOTI and TROPOS studies to evaluate the efficacy and safety of strontium ranelate up to 10 years.

\section{Methods}

Study design and patients

The procedures for the open-label extension study of SOTI and TROPOS have been described extensively elsewhere [13]. The initial 3-year extension (8 years' continuous treatment) was increased by 2 years to reach a total of 10 years' continuous follow-up. The 10-year extension study therefore enrolled postmenopausal women with osteoporosis who had completed 5 years of treatment with strontium ranelate or placebo in the SOTI and TROPOS studies (years 0 to 5 ) plus a further 5 years of treatment in the extension phase (years 6 to 10) $[9,10]$ (Fig. 1). The main reasons for not continuing were either patient's own personal decision or investigator's decision according to the patient's status (e.g. age or mobility). During the open-label extension, all patients received strontium ranelate $2 \mathrm{~g} /$ day, as well as calcium $(<1000 \mathrm{mg} /$ day) and vitamin D (400 to $800 \mathrm{IU} /$ day). All patients gave written informed consent before inclusion in both parts of the extension study (at year 6 and year 9), which was approved by institutional ethics review committees. In this article, results will be restricted to the 10 -year population $(n=237)$, i.e. patients from the active treatment arms of SOTI and TROPOS who received strontium ranelate for up to 10 years.

\section{Efficacy endpoints}

The main efficacy endpoints were the incidence of new osteoporotic fractures and the change in lumbar spine, femoral neck, and total hip BMD between years 6 and 10 . The procedures used to evaluate the incidence of fractures are described in detail in the original reports $[9,10,13]$. All patients from the SOTI trial had spinal X-rays at inclusion and yearly thereafter. The patients from the TROPOS study 


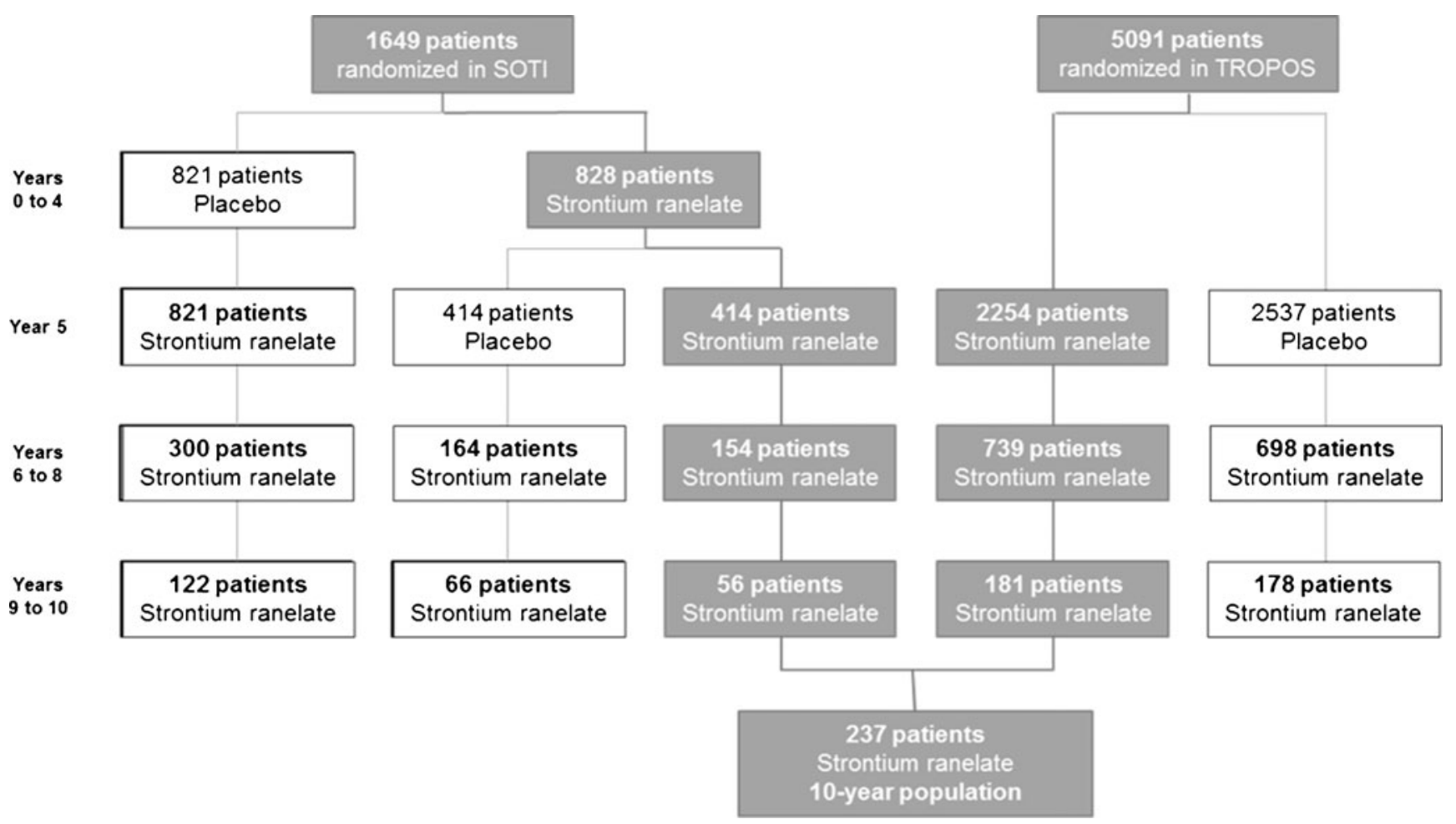

Fig. 1 Flow of patients

in whom spinal X-rays were routinely performed continued to have them in the extension phase. Spinal X-rays were read centrally and incident vertebral fracture detected by semi-quantitative assessment and grading [14]. Clinical peripheral (nonvertebral) osteoporosis-related fractures were assessed in all patients according to radiological evaluation and written documentation (radiological, hospitalization, or emergency room report). All peripheral fractures (including hip) were considered as osteoporosis-related, except when they concerned the skull, face or jaw, coccyx, phalanx (fingers or toes), or ankle. New fracture was defined as the occurrence of a new vertebral, nonvertebral, or hip fracture in years 6 to 10, independently of any fracture incurred in years 0 to 5 (which were considered as previous fractures for the purposes of the extension study).

BMD was measured by dual energy X-ray absorptiometry (DXA, Hologic) at entry to the extension study (year 6) and yearly thereafter, using the same acquisition program and quality control as the original studies $[9,10,15]$.

$\operatorname{FRAX}^{\circledR}[16,17]$ was used to evaluate individual patients' risk of fracture in the 10 -year population at 5 years. The FRAX ${ }^{\circledR}$ algorithm integrates a number of clinical risk factors, including BMD at the femoral neck, to give a 10year probability of hip or major osteoporotic fracture (clinical vertebral, forearm, hip, or shoulder fracture). In this study, FRAX was calculated without BMD in patients previously treated with strontium ranelate for 5 years.
Safety and compliance

Blood and urine chemistry, hematology, and blood strontium were assessed every 12 months. Adverse events were collected at each 6-month visit. Patient compliance was assessed by the number of unused sachets returned every 6 months.

\section{Statistical methods}

The baseline characteristics of the 10 -year population at year 0 are presented as mean \pm SD for continuous variables and number of patients (\%) for categorical variables. The analysis was performed in the full analysis set (FAS) comprising all patients who had at least one intake of strontium ranelate after inclusion at year 9, at least one measurement of lumbar spine L2-L4 BMD at baseline (year 9) and between years 9 and 10, and at least one evaluation of fracture between years 9 and 10. Cumulative incidence of new vertebral, nonvertebral, or any osteoporotic fracture was estimated by the Kaplan-Meier method in the first 5 years (years 0 to 5 ) and in the 5 years of the extension study (years 6 to 10). McNemar's test was used to compare the number of patients experiencing at least one fracture during the first 5 years in the 10 -year population with that of patients experiencing at least one new fracture during the 5 years of the extension study. Change in BMD 
and relative change from baseline to each visit were calculated and compared within the group (previous year) using a Student $t$ test for paired samples.

To assess the long-term antifracture efficacy of strontium ranelate in the absence of a placebo group, we sought a matching population in the placebo group of TROPOS (years 0 to 5). In this post-hoc exploratory analysis, 10-year fracture probabilities for major osteoporotic fracture in the 10 -year population and in the FRAX $^{\circledR}$-matched placebo population were calculated as mean values of the individual FRAX $^{\circledR}$ probabilities. To ensure the comparability of the two populations, we identified patients in the placebo group with the same FRAX ${ }^{\circledR}$ score, i.e. 10-year probability of major osteoporotic fracture, at baseline (year 0) as the 10year population at entry to the extension study (year 6) using a modified case-control analysis with a ratio of two patients from TROPOS to one patient from the extension study. This FRAX ${ }^{\circledR}$-matched placebo population comprised 458 patients. The Greedy's algorithm (an optimal version of the $k$-means method) with six clusters was used.

A $P$ value of 0.05 or less was considered significant. Statistical analysis was performed using SAS/PC software version 9.1.

\section{Results}

\section{Patient characteristics}

The 10-year extension study was performed in 36 centers in eight European countries and Australia. Out of the 2055 patients who entered the extension study at 5 years, 1420 (69\%) completed the 3 -year treatment period to 8 years. A total of 603 patients accepted to participate in the 2-year prolongation of the extension study to 10 years, of whom 237 had been treated with strontium ranelate for 8 years (i.e. the 10 -year population, Fig. 1). The 10-year population consisted of 233 patients (56 from SOTI and 177 from TROPOS; four patients excluded since they did not take the study treatment). The characteristics of the 10 -year population at year 0 were similar to those of the two main study populations at year 0 (Table 1).

The mean persistence with strontium ranelate in the 10year population was $117.8 \pm 6.1$ months (i.e. 9 years and 9 months); the mean compliance was $89.4 \pm 12.6 \%$. Blood strontium values reached a plateau after 3 months of treatment. Mean values of blood strontium ranged from $136.1 \pm 89.3$ to $158.8 \pm 105.7 \mu \mathrm{mol} / \mathrm{L}$ and were consistent with good exposure to the treatment over 10 years.

\section{Fractures}

The cumulative incidence of new fracture in the 10-year population in years 6 to 10 was similar to the cumulative incidence in years 0 to 5 (vertebral fracture: $20.6 \pm 3.0 \%$ versus $18.5 \pm 2.6 \%$, respectively, $P=1.00$; non-vertebral fracture: $13.7 \pm 2.3 \%$ versus $12.9 \pm 2.2 \%, P=0.672$; and any osteoporotic fracture: $30.3 \pm 3.1 \%$ versus $27.5 \pm 2.9 \%, P=$ 0.734) (Fig. 2). The 10-year population had a mean FRAX $^{\circledR} 10$-year probability of major osteoporotic fracture (calculated without BMD) of $25.8 \pm 9.6 \%$ at the time of their inclusion in the extension study (at year 6).

The effect of strontium ranelate on fracture incidence was evaluated by comparison with a FRAX $^{\circledR}$-matched placebo group identified in the TROPOS placebo arm. The FRAX $^{\circledR}$-matched placebo population of TROPOS had a mean FRAX ${ }^{\circledR} 10$-year probability of major osteoporotic fracture of $25.8 \pm 9.3 \%$ at the baseline (year 0 ). The patients in these two populations were similar in terms of age, BMI, time since menopause, parental history of osteoporotic fracture, and prevalence of osteoporotic fracture (Table 2). The cumulative incidences of fracture in the 10-year population were compared with the cumulative incidence of fracture in the $\mathrm{FRAX}^{\circledR}$-matched placebo population
Table 1 Baseline characteristics at year 0

$B M D$ bone mineral density

${ }^{\mathrm{a}}$ Randomized set SOTI and TROPOS excluding the 10 -year population

\begin{tabular}{lll}
\hline & $\begin{array}{l}\text { Pooled SOTI and } \\
\operatorname{TROPOS}^{\mathrm{a}}(n=6503)\end{array}$ & $\begin{array}{l}10 \text {-Year population } \\
(n=237)\end{array}$ \\
\hline Age (years) & $75.2 \pm 6.4$ & $72.0 \pm 5.4$ \\
Body mass index $\left(\mathrm{kg} / \mathrm{m}^{2}\right)$ & $25.65 \pm 4.09$ & $25.80 \pm 3.82$ \\
Time since menopause (years) & $27.4 \pm 8.3$ & $23.65 \pm 6.81$ \\
$\geq 1$ Prevalent nonvertebral fracture, $n(\%)$ & $2365(36)$ & $103(44)$ \\
$\geq 1$ Prevalent vertebral fracture, $n(\%)$ & $2857(44)$ & $100(45)$ \\
Lumbar BMD $\left(\mathrm{g} / \mathrm{cm}^{2}\right)$ & $0.781 \pm 0.152$ & $0.755 \pm 0.136$ \\
T-score & $-3.00 \pm 1.52$ & $-3.266 \pm 1.420$ \\
Femoral neck BMD $\left(\mathrm{g} / \mathrm{cm}^{2}\right)$ & $0.561 \pm 0.075$ & $0.576 \pm 0.063$ \\
T-score & $-3.06 \pm 0.67$ & $-2.946 \pm 0.566$ \\
Total hip BMD $\left(\mathrm{g} / \mathrm{cm}^{2}\right)$ & $0.658 \pm 0.102$ & $0.688 \pm 0.089$ \\
T-score & $-2.64 \pm 1.00$ & $-2.344 \pm 0.876$ \\
\hline
\end{tabular}



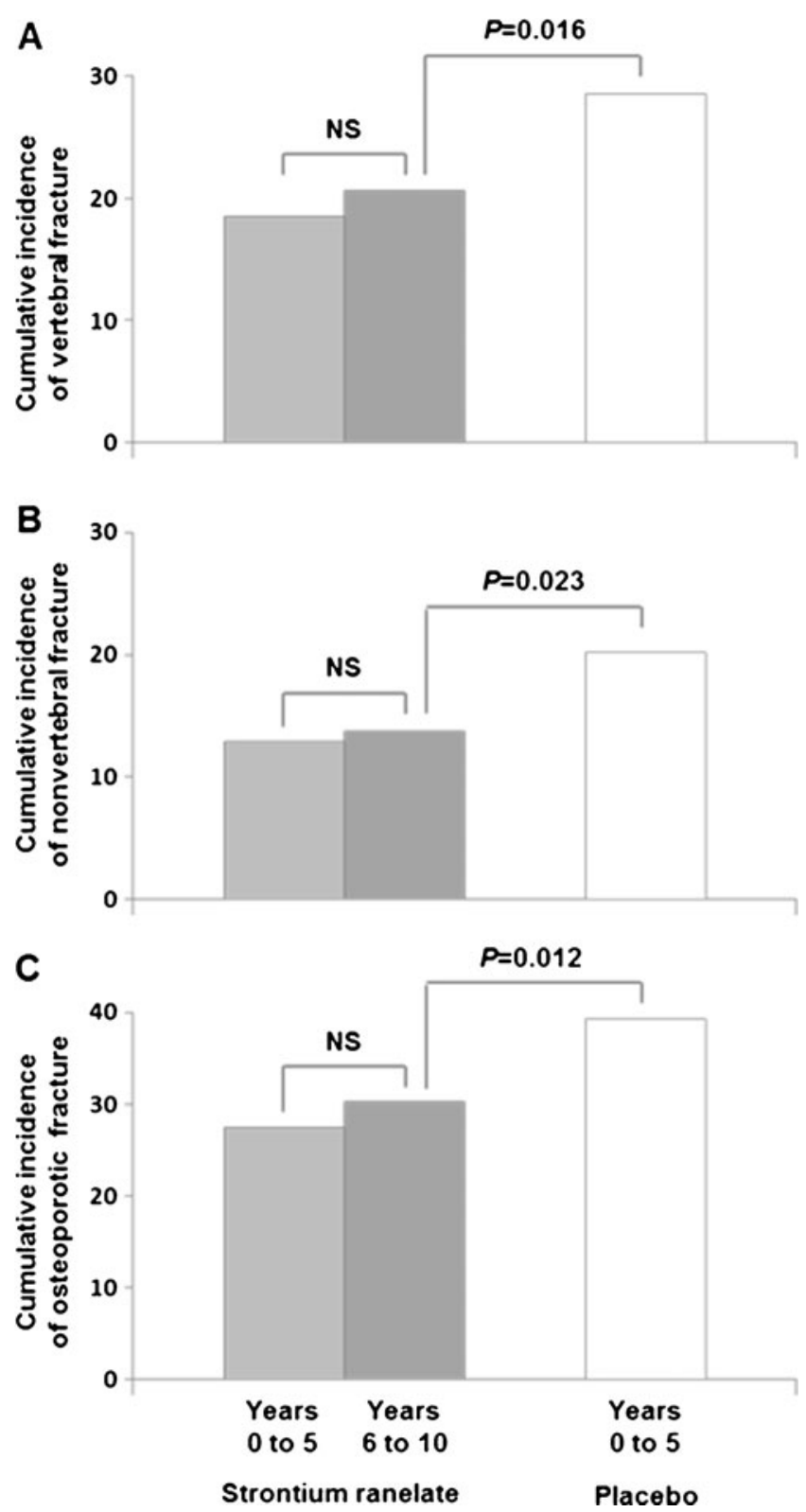

Fig. 2 Cumulative incidence of new vertebral fracture (A), new nonvertebral fracture (B), and new osteoporotic fracture $(\mathbf{C})$ in the 10year population between 0 and 5 years' treatment with strontium ranelate and between 6 and 10 years' treatment with strontium ranelate (gray bars) and in the FRAX ${ }^{\circledR}$-matched placebo group of TROPOS between 0 and 5 years (white bars)
(Fig. 2). The cumulative incidence of new vertebral fractures in the 10-year population in years 6 to 10 was significantly lower than that observed over 5 years in the FRAX $^{\circledR}$-matched placebo population $(20.6 \pm 3.0 \%$ versus $28.2 \pm 2.4 \%$, respectively; relative reduction in risk [RRR] $35 \%, P=0.016$ ). Similarly, the 10 -year population had significantly lower rates of nonvertebral fracture and new osteoporotic fracture in years 6 to 10 than the FRAX $^{\circledR}$ matched placebo population over 5 years (nonvertebral fracture: $13.7 \pm 2.3 \%$ versus $20.2 \pm 2.2 \%$, respectively, RRR $38 \%, P=0.023$; new osteoporotic fracture: $30.3 \pm 3.1 \%$ versus $39.2 \pm 2.5 \%$, RRR $30 \%, P=0.012$ ).

Bone mineral density

Over the 10-year period, lumbar BMD increased continuously with a mean relative change from baseline of $34.5 \pm 20.2 \%$ (Table 3 ) in the 10-year population treated with strontium ranelate. At this site, the annual change remained significant over the whole 10 -year period $(P<0.001$ up to year 9 and $P=$ 0.002 for the last year). After 10 years' treatment with strontium ranelate, the mean relative changes in BMD from baseline were $10.7 \pm 12.1 \%$ at the femoral neck and $11.7 \pm$ $13.6 \%$ for total hip. At both sites, the BMD increased significantly until year 7 and remained stable thereafter.

Correlation between changes in BMD and incidence of fracture

Our analysis included 116 women with femoral neck and total hip BMD and fracture data available over the 10 years of follow-up. During the last 2 years of follow-up, 12 of these patients experienced a new vertebral fracture. After having controlled for age, body mass index at year 9, BMD at year 9, number of vertebral fractures at year 0 , and number of new vertebral fractures from years 0 to 8 , we found that the change in femoral neck BMD from years 9 to 10 was significantly associated with vertebral fractures incidence during the same period of time $(P=0.03)$. Each $1 \%$ increase in femoral neck BMD was associated with a $15 \%$ (95\% adjusted confidence interval [CI] 2-26\%) decrease in risk for new vertebral fracture. The same trend
Table 2 Main characteristics of the FRAX ${ }^{\circledR}$-matched groups at year 0 , in comparison with the characteristics of the 10-year population at 5 years

\begin{tabular}{lcc}
\hline & $\begin{array}{l}\text { 10-Year population } \\
\text { at } 5 \text { years }(n=233)\end{array}$ & $\begin{array}{c}\text { TROPOS FRAX } \\
\text { placebo } \text {-matched }\end{array}$ \\
\hline FRAX score (\%) & $25.8 \pm 9.6$ & $25.8 \pm 9.3$ \\
Age (years) & $77.3 \pm 5.3$ & $76.3 \pm 4.7$ \\
Body mass index $\left(\mathrm{kg} / \mathrm{m}^{2}\right)$ & $25.8 \pm 4.1$ & $25.2 \pm 3.7$ \\
Time since menopause (years) & $28.4 \pm 6.8$ & $28.4 \pm 7.4$ \\
Parental history of osteoporotic fracture, $n(\%)$ & $92(39)$ & $146(32)$ \\
$\geq 1$ Prevalent osteoporotic fracture, $n(\%)$ & $177(76)$ & $309(67)$ \\
\hline
\end{tabular}


Table 3 Change in bone mineral density (BMD) in patients treated with strontium ranelate for 10 years
$* P<0.05 ; * * P<0.01$ $* * * P<0.001$, for within-group comparison

\begin{tabular}{lccc}
\hline & No. of patients & Mean change $\left(\mathrm{g} / \mathrm{cm}^{2}\right)$ & $\begin{array}{c}\text { Mean relative change } \\
\text { from baseline (\%) }\end{array}$ \\
\hline $\begin{array}{l}\text { Lumbar spine L2-L4 } \\
\text { Baseline to year 10 }\end{array}$ & 155 & $0.253 \pm 0.151^{* * *}$ & $34.5 \pm 20.2^{* * *}$ \\
Years 0-5 & 223 & $0.179 \pm 0.105^{* * *}$ & $23.9 \pm 13.9^{* * *}$ \\
Years 6-10 & 146 & $0.070 \pm 0.115^{* *}$ & $7.9 \pm 12.6^{* *}$ \\
Femoral neck & 147 & & $10.7 \pm 12.1^{* * *}$ \\
Baseline to year 10 & 225 & $0.060 \pm 0.066^{* * *}$ & $8.8 \pm 8.0^{* * *}$ \\
Years 0-5 & 130 & $0.050 \pm 0.044^{* * *}$ & $1.8 \pm 9.1^{*}$ \\
Years 6-10 & & $0.010 \pm 0.056^{*}$ & $11.7 \pm 13.6^{* * *}$ \\
Total hip & 147 & & $12.1 \pm 11.2^{* * *}$ \\
Baseline to year 10 & 225 & $0.077 \pm 0.084^{* * *}$ & $0.04 \pm 8.9$ \\
Years 0-5 & 130 & $0.080 \pm 0.056^{* * *}$ & $0.000 \pm 0.067$ \\
Years 6-10 & & & \\
\hline
\end{tabular}

was observed for total hip BMD (7\%; 95\% CI 3-17\%), but did not reach statistical significance $(P=0.16)$. Women with new vertebral fractures from years 9 to 10 experienced a simultaneous decrease of $2.4 \pm 4.7 \%$ in femoral neck BMD, compared with an increase of $1.5 \pm 8.3 \%$ in women without new vertebral fracture.

\section{Safety}

During the extension study, 226 patients $(95 \%)$ in the 10 year population reported at least one emergent adverse event on treatment. The comparison of the incidences of the most frequent adverse events observed with strontium ranelate in the 5 years of the SOTI and TROPOS studies and those in years 6 to 10 (Table 4) shows no increase after long-term use in an aging population. The annual incidence of events related to venous thromboembolism in patients treated with strontium ranelate during the 5 years of the extension study (i.e. patients who had received treatment for 10 years) was $0.4 \%$. The neurological disorders reported included memory losses (annual incidence 1.1\%) and disturbances in consciousness (annual incidence $0.8 \%$ ), but no case of seizure. Moreover, no new signal was detected over the last 2 years of the extension study; no cases of drug-related hypersensitivity reactions were reported in the extension study.

\section{Discussion}

Our results indicate a stable fracture rate and maintenance of BMD with strontium ranelate treatment over 10 years, despite an increase in age and prevalent fractures in the population. The major result of our study is the comparable cumulative incidences of vertebral and nonvertebral fracture in the same population over two consecutive 5-year periods. The significantly lower rate of fracture than the FRAX ${ }^{\circledR}$-matched placebo group could be considered as indirect evidence for the sustained antifracture efficacy of strontium ranelate over 10 years of treatment. Our findings also support the safety of strontium ranelate up to 10 years' treatment, with rates of events related to venous thromboembolism and neurological disorders in accordance with those observed over 5 years in the original studies.
Table 4 Adverse events reported during the extension study compared with those reported in the 5 years of the SOTI and TROPOS trials in patients receiving strontium ranelate

\begin{tabular}{lrl}
\hline & $\begin{array}{l}\text { Pooled SOTI-TROPOS strontium } \\
\text { ranelate group }(n=3352) \\
0-5 \text { years }\end{array}$ & 10-Year population $(n=237)$ \\
& $6-10$ years \\
\hline $\begin{array}{l}\text { Nervous system disorder } \\
\text { Headache }\end{array}$ & $112(3.3 \%)$ & $3(1.3 \%)$ \\
Gastrointestinal disorder & $239(7.1 \%)$ & $2(0.8 \%)$ \\
Nausea & $234(7.0 \%)$ & $11(4.6 \%)$ \\
Diarrhea & $76(2.3 \%)$ & $0(0.0 \%)$ \\
Skin and subcutaneous tissue disorder \\
Dermatitis \\
Eczema & $59(1.8 \%)$ & $3(1.3 \%)$ \\
\hline
\end{tabular}


Long-term trials are not simple to perform, and extension studies are fraught with methodological problems associated with an open-label design, small samples, and the absence of a placebo control. In osteoporosis, this renders antifracture efficacy difficult to evaluate, decreasing the reliability of the results [18]. Long-term treatment with alendronate has been explored in an extension study, in which patients who had received 5 years' treatment entered a 5-year extension with alendronate or placebo [2]. The objective was to assess the effects of continuation or discontinuation of alendronate on BMD after 5 years' treatment, while the incidence of fracture constituted an exploratory endpoint only. There was a continuous increase in BMD at the lumbar spine with long-term alendronate, and plateaus at the other sites. Despite the small but statistically significant between-group differences in BMD, there was no increase in morphometric vertebral or nonvertebral fractures among patients who discontinued versus those who continued alendronate. However, there was a $2.9 \%$ significant absolute risk increase in clinical spine fracture in patients who discontinued treatment. Another alendronate study [19] showed similar effects on BMD after 10 years' treatment, but again could not conclude on vertebral fracture incidence, which was assessed as a safety rather than efficacy endpoint. Similar results were reported for risedronate in a study in which 83 patients continued for 7 years [1].

Another agent that has been tested long term is raloxifene, for which results over 8 years in women with breast cancer showed maintenance of the increases in lumbar spine and femoral neck BMD, but was inconclusive on fracture risk [4, 5]. Results for denosumab indicate continuous increases in BMD over 5 to 6 years at all sites with incidences of vertebral and nonvertebral fracture below rates observed in the phase 3 placebo group $[6,7]$.

The main reason for the difficulties in demonstrating an impact on fracture incidence in these long-term studies is the absence of a placebo control. One solution is to compare fracture incidence with the first years of the study, in which efficacy versus placebo has already been demonstrated. Thus, the 8-year pooled analysis of SOTI and TROPOS reported no statistical difference between incidence of fracture in the first 3 years of the trials (years 0 to 3 ) and the first 3 years of the extension (years 6 to 8 ) for vertebral, nonvertebral, or any osteoporotic fracture [13]. Our finding of similar rates in the first 5 years (years 0 to 5 ) and the last 5 years (years 6 to 10 ) reinforces the conclusion that the antifracture efficacy of strontium ranelate is sustained in the long-term. However, we also compared these cumulative incidences with those in a FRAX ${ }^{\circledR}$-matched placebo population in the TROPOS study in an exploratory post hoc analysis. The advantage of FRAX ${ }^{\circledR}$ is that it provides estimates of 10-year fracture risk [16, 17], presenting the opportunity to identify patients at the same level of risk at the beginning of a 5 -year observation period, as the 10 -year population at year 5 , reducing confounders such as aging of the population, prevalent fracture, and other risk factors. We used FRAX ${ }^{\circledR}$ scores calculated without BMD in patients already treated with strontium ranelate for 5 years, precluding any potential bias related to the effect of treatment on BMD. On the other hand, FRAX ${ }^{\circledR}$ does not account for the number and severity of prevalent fractures, which is a limitation of the tool. Our results of lower rates of fracture in the patients between 5 and 10 years of treatment versus this matched placebo group strongly support sustained long-term antifracture efficacy of strontium ranelate over 10 years.

Our observation of a similar efficacy between 6 and 10 years as in the first 5 years of treatment is also in line with the reported absence of influence of age, baseline $\mathrm{BMD}$, or other risk factors on the efficacy of strontium ranelate [11]. Moreover, a recent analysis by Kanis confirmed that the efficacy of strontium ranelate in clinical and morphometric fracture did not depend on baseline fracture risk assessed by FRAX ${ }^{\circledR}[20]$, whereas the same analyses performed with antiresorptive agents such as denosumab [21] and clodronate [22] indicated efficacy against clinical osteoporotic fracture in patients at moderate and/or high risk only. The levels of compliance with strontium ranelate over 10 years compare well with those reported in the long-term studies with alendronate [2, 23], even considering the design of this extension study, in which the patients themselves chose to continue treatment.

Our study has the limitations of many long-term trials in the management of a chronic disease (absence of comparator, small sample size, and open-label design). The absence of placebo group in the second 5-year period precluded any direct demonstration of antifracture efficacy, and so only indirect comparisons were possible. Participation in the extension was based on the patients' decision, which could have resulted in selection bias. The aging of the population may also have had an impact, with elderly patients being less likely to continue. On the other hand, baseline characteristics showed that the 10-year population was representative of the original populations. One limitation of the comparison with the FRAX ${ }^{\circledR}$-matched placebo may be that the patients in the 10 -year population were treated prior to entry into the extension phase. Another limitation is that the fracture incidences in the $\mathrm{FRAX}^{\circledR}$-matched placebo group are peripheral fracture, whereas FRAX $^{\circledR}$ predicts the 10-year probability of major osteoporotic fracture, defined as clinical spine, forearm, humerus, or hip fracture. In this context, the incidence of major osteoporotic fracture in the 10-year population was $16.0 \pm 2.4 \%$ during the 5-year extension study, which should be compared with the 10-year probability of $25.8 \pm 9.6 \%$ given by $\mathrm{FRAX}^{\circledR}$ and the incidence of major osteoporotic fracture in the TROPOS placebo group over 
5 years, which was $21.2 \pm 2.1 \%$. Clearly, a long-term placebocontrolled trial would be the best source of information on the benefits of long-term treatment. However, once efficacy has been demonstrated in relatively short-term trials, it is not possible to conduct long-term, placebo-controlled trials for ethical reasons, particularly in studies including patients at high risk of fracture. A new method for simulating the longterm effects of treatment using data from placebo-controlled trials with extensions was recently proposed by Vittinghoff [24] and applied retrospectively to long-term data for alendronate with limited results. This is not a commonly used method that has also several limitations, in that it requires substantial assumptions and does not entirely control for potential selection and secular effects.

In conclusion, the management of patients with postmenopausal osteoporosis should include a treatment with both sustained antifracture efficacy in the long-term and a safe long-term profile. Long-term treatment with strontium ranelate is associated with sustained increases in BMD over 10 years, with a good tolerance. Our results also support the maintenance of antifracture efficacy over 10 years with strontium ranelate.

Acknowledgments We would like to thank all investigators of this study as well as Pr D. Slosman and C. Perron for the central reading of DXA scans and C.Roux and J. Fechtenbaum for the central reading of X-rays.

\section{Conflicts of interest None.}

Open Access This article is distributed under the terms of the Creative Commons Attribution Noncommercial License which permits any noncommercial use, distribution, and reproduction in any medium, provided the original author(s) and source are credited.

\section{References}

1. Mellstrom DD, Sorensen OH, Goemaere S et al (2004) Seven years of treatment with risedronate in women with postmenopausal osteoporosis. Calcif Tissue Int 75:462-8

2. Black DM, Schwartz AV, Ensrud KE et al (2006) Effects of continuing or stopping alendronate after 5 years of treatment: the Fracture Intervention Trial Long-term Extension (FLEX): a randomized trial. JAMA 296:2927-38

3. Black DM, Reid I, Cauley J et al. (2010) The effect of 3 versus 6 years of zoledronic acid treatment in osteoporosis: a randomized extension to the HORIZON-Pivotal Fracture Trial (PFT). Abstract 1070. J Bone Miner Res 25 (suppl 1):

4. Martino S, Cauley JA, Barrett-Connor E et al (2004) Continuing outcomes relevant to Evista: breast cancer incidence in postmenopausal osteoporotic women in a randomized trial of raloxifene. J Natl Cancer Inst 96:1751-61

5. Siris ES, Harris ST, Eastell R et al (2005) Skeletal effects of raloxifene after 8 years: results from the continuing outcomes relevant to Evista (CORE) study. J Bone Miner Res 20:1514-24
6. Papapoulos S, Man Z, Mellstrom D et al (2011) Five-year denosumab treatment of postmenopausal women with osteoporosis: results from the first two years of the FREEDOM trial extension. OC24. Osteoporos Int 22(suppl 1):S107

7. Miller PD, Wagman RB, Peacock M et al (2011) Effect of denosumab on bone mineral density and biochemical markers of bone turnover: six-year results of a phase 2 clinical trial. J Clin Endocrinol Metab 96:394-402

8. Marie PJ (2007) Strontium ranelate: new insights into its dual mode of action. Bone 40:S5-S8

9. Meunier PJ, Roux C, Seeman E et al (2004) The effects of strontium ranelate on the risk of vertebral fracture in women with postmenopausal osteoporosis. N Engl J Med 350:459-68

10. Reginster JY, Seeman E, De Vernejoul MC et al (2005) Strontium ranelate reduces the risk of nonvertebral fractures in postmenopausal women with osteoporosis: Treatment of Peripheral Osteoporosis (TROPOS) study. J Clin Endocrinol Metab 90:2816-22

11. Roux C, Reginster J-Y, Fechtenbaum J et al (2006) Vertebral fracture risk reduction with strontium ranelate in women with postmenopausal osteoporosis is independent of baseline risk factors. J Bone Miner Res 21:536-42

12. Reginster JY, Felsenberg D, Boonen S et al (2008) Effects of longterm strontium ranelate treatment on the risk of non-vertebral and vertebral fractures in postmenopausal osteoporosis: results of a 5-year, randomized, placebo-controlled trial. Arthritis Rheum 58:1687-95

13. Reginster JY, Bruyere O, Sawicki A et al (2009) Long-term treatment of postmenopausal osteoporosis with strontium ranelate: results at 8 years. Bone 45:1059-64

14. Genant HK, Wu CY, Van Kuijk C et al (1993) Vertebral fracture assessment using a semiquantitative technique. J Bone Miner Res 8:1137-48

15. Slosman DO, Provvedini DM, Meunier PJ et al (1999) The use of different dual X-ray absorptiometry brands in a multicenter clinical trial. Consequences and limits J Clin Densitom 2:37-44

16. Kanis JA, Johnell O, Oden A et al (2008) FRAX and the assessment of fracture probability in men and women from the UK. Osteoporos Int 19:385-97

17. WHO Collaborating Centre for Metabolic Bone Diseases (2008) FRAX WHO fracture risk assessment tool. Available at: http:// www.shef.ac.uk/FRAX/. Accessed 27 April 2011

18. Briot K, Tremollieres F, Thomas T et al (2007) How long should patients take medications for postmenopausal osteoporosis? Joint Bone Spine 74:24-31

19. Bone HG, Hosking D, Devogelaer JP et al (2004) Ten years' experience with alendronate for osteoporosis in postmenopausal women. N Engl J Med 350:1189-99

20. Kanis JA, Johansson H, Oden A et al. (2011) A meta-analysis of the effect of strontium ranelate on the risk of vertebral and nonvertebral fracture in postmenopausal osteoporosis and the interaction with $\operatorname{FRAX}((\mathrm{R}))$. Osteoporos Int In press

21. McCloskey E, Johansson H, Oden A et al. (2011) Denosumab reduces the risk of clinical osteoporotic fractures in postmenopausal women, particularly in those with moderate to high fracture risk as assessed with FRAX. Abstract OC15. Osteoporos Int 22 (suppl 1):S103

22. McCloskey EV, Johansson H, Oden A et al (2009) Ten-year fracture probability identifies women who will benefit from clodronate therapy-additional results from a double-blind, placebo-controlled randomised study. Osteoporos Int 20:811-7

23. Cummings SR, Black DM, Thompson DE et al (1998) Effect of alendronate on risk of fracture in women with low bone density but without vertebral fractures: results from the Fracture Intervention Trial. JAMA 280:2077-82

24. Vittinghoff E, McCulloch CE, Woo C et al (2010) Estimating long-term effects of treatment from placebo-controlled trials with an extension period, using virtual twins. Stat Med 29:1127-36 